\title{
Diversity in Australian higher education?
}

\author{
LEO C.J. GOEDEGEBUURE ${ }^{1}$, ART LYSONS ${ }^{2} \&$ V. LYNN MEEK ${ }^{3}$ \\ ${ }^{1}$ Center for Higher Education Policy Studies, University of Twente, The Netherlands, ${ }^{2}$ Department of \\ Management, James Cook University of North Queensland, Australia, ${ }^{3}$ Department of Administrative, \\ Higher and Adult Education Studies, University of New England, Australia
}

\begin{abstract}
This study explores systematic relationships between management attitudes about recent transitions in the funding and structure of higher education in Australia (Meek and Goedegebuure, 1989) and the domains of the taxonomy emerging from ongoing organisational effectiveness research based on these institutions (Lysons, 1990b). The results reinforce the integrity of the previously established 4 group framework and flesh-out more fine-grained issues which may militate against the smooth transition of amalgamated institutions to university status, on the one hand, and the enhancement of diversity on the other.
\end{abstract}

\section{Introduction}

Australian higher education has experienced major restructuring following the publication of Higher Education: a policy discussion paper (known as the Green Paper) in late 1987. The then Minister for Employment, Education and Training, the Hon. John Dawkins, announced amongst other things, the demise of the socalled binary system which distinguished universities from colleges of advanced education (CAEs) for funding and other purposes. Universities were funded for teaching and research, while the colleges were confined mainly to teaching in the more technical/vocational fields. Now nearly all higher education institutions are called universities. But in creating the new Unified National System (UNS) of higher education, the government has insisted that it does not intend to create a unitary system. The Green Paper stated that government would fund institutions for what they do, not for what they are called, and every official statement on higher education since the Green Paper has stressed the need for a more diverse and responsive set of higher education institutions (for the most recent statement, see Higher Education: Quality and Diversity, 1991). At the same time, however, it appears that some government policies are contradictory in outcome in that they may encourage institutional imitation rather than diversification. Also, some policy contradictions may have been avoided had government better recognised the character and structure of existing institutional diversity.

It may seem somewhat paradoxical that a government, in order to enhance diversity, would abolish a binary system which formally distinguished institutions by function. But one of the primary criticisms of the old binary system was that while official policy was based on the assumption of uniformity within sectors and significant divergence between sectors, in reality the opposite was the case. Even though there were important differences between institutions with respect to such 
factors as status and prestige, management style and culture, and capacity to effectively deliver particular educational and research programs, system-wide policies governing competition over scarce resources seemed to encourage an unhealthy duplication of function and programs.

The CAEs began in the mid-1960s as non-degree awarding postsecondary institutions, but very quickly shed sub-degree diplomas and certificates in favour of degrees and postgraduate awards. By 1987, most CAEs were campaigning for equality of research funding with universities, and several CAEs were about to be reclassified by their state governments as universities. The Dawkins reforms probably were a necessary reaction to intense binary competition. But the reforms were one dimensional in that they concentrated on removing the binary divide, which had ceased to have any useful function, while not strengthening the institutional diversity already present within the system. The reforms resulted in the reduction of Australia's existing 19 universities and 44 CAEs to 36 universities in 1991, mostly through amalgamations; a process that is still continuing, thus reducing the number of institutions even further. This massive institutional reorganisation failed, in many instances, to take account of existing institutional orientation and type, which has resulted in instability amongst several of the amalgamations. Also, the reward structure upon which the new UNS is based may, as indicated above, encourage institutional imitation. We will return to these themes in the conclusion, but first it is worthwhile to explore empirical evidence relating to the taxonomy of Australian higher education just prior to and during its transformation to the UNS.

Further to the binary distinction between universities and CAEs, an important research finding concerning Australian higher education prior to the Dawkins reforms was that the system consisted of four discrete groups each servicing separate domains (Lysons, 1990b). The organisational effectiveness (OE) taxonomy which emerged from this research program highlighted the differences in 'academic' and 'student drawing power' orientations existing in the system during the 1980s. The distinctive groups included larger/older universities, smaller/younger universities, institutes of technology, and colleges. Although these categories were defined by aspects strikingly similar to those emerging in Cameron's $(1978 ; 1981)$ work in the US, there were some interesting distinctions. The main difference was the apparent importance of organisational climate issues in effectiveness, and in particular how two leadership dimensions - facilitative supportive versus goal directed - featured in a contingency pattern relative to each type of institution. Although these results were intuitively meaningful and useful to management at the time, the recent events in Australia appear to have changed the face of higher education dramatically. But, as will be discussed later, systems destabilised appear to have a remarkable capacity to resurrect themselves in the light of past images.

In this article, we are primarily concerned with only two aspects of the restructuring process: (1) the abolition of the binary system and its replacement by the new UNS of higher education, and (2) the impact of consolidation of institutions through amalgamations on system taxonomy. We are not concerned 
here with the means by which amalgamations have been achieved.

The restructuring of Australian higher education has been the subject of a major study by Meek and Goedegebuure (1989) which endeavoured to capture the impact of government policy on institutional management, funding and resources, the quality of educational outcomes, and the overall impact of amalgamations. This article explores the relationships between these data on transitional management issues and the management effectiveness taxonomy derived from survey research prior to the demise of the binary system and the recent amalgamations (Lysons, $1990 \mathrm{~b} ; 1993$ ), and draws some tentative conclusions regarding the further development of the Australian higher education system with respect to the roles of the former CAEs and the established universities.

\section{Theoretical rationale and method}

The primary thrust of this endeavour is to analyse the recent changes with which Australian higher education has been confronted in relation to one of the principle objectives of governments reform policy, namely the perceived need to further diversify the higher education system. In order to carry out this analysis, we draw upon two research studies: the Lysons taxonomy that identified different groups of Australian higher education institutions; and the Meek and Goedegebuure study on management perceptions of recent changes in higher education. The theories underpinning the Lysons taxonomy included the systems resource model (Yuchtman and Seashore, 1967; Pfeffer and Salancik, 1978) explaining differences in effectiveness orientation on either side of the former binary line between universities and other institutions, and life cycle theory (Cameron and Whetten, 1981; Quinn and Cameron, 1983; Quinn and Rohrbaugh, 1983) which explains fundamental differences between the four vintages of institutions as outlined by Karmel (1989): larger/older universities, smaller/younger universities, institutes of technology and colleges.

The theoretical basis of this study is first, that the dimensions proven to be reliable through replication (Lysons, 1993) demonstrate consistent discriminant validity in terms of the four groups hypothesised (Lysons, 1990b). Secondly, that the nature of these dimensions, their discriminant functions and the intuitive meaningfulness of the groupings strongly suggest quite distinctive organisational cultures (Lysons, 1990b). And finally that, in such circumstances, systems resource and organisational theory would suggest that although vast and rapid change in terms of the system's structure is feasible (Goedegebuure and Meek, 1991), more fundamental change in terms of the actual functioning of higher education institutions and their relationships can only be achieved incrementally and slowly (e.g., Becher and Kogan, 1980, Clark, 1983, Van Vught, 1989). This hypothesis is contrary to the expectations underlying the Australian government's recent attempts to externally affect the rate and nature of change in the higher education system (Dawkins, 1988; Task Force on Amalgamations, 1989).

The approach in this article is therefore to identify logical dimensions of 
management perceptions regarding transitional issues and attitudes in relation to the overall impact of amalgamations from the Meek and Goedegebuure (1989) study, to test whether in fact they systematically reflect differences implicitly hypothesised by the taxonomy of Australian higher education derived from previous studies (Lysons, 1990b; 1993), and discuss the effects of this in terms of the new institutional constellation that has emerged as a result of the government induced amalgamations.

\section{Sample and analysis}

The Meek and Goedegebuure survey was conducted by means of a questionnaire, directed at key position holders in the field of higher education: Chairmen of Council, Executive Officers and Registrars/Secretaries of colleges, institutes and universities, as well as key position holders of external agencies like, e.g., state coordinating bodies. Their response was substantial (73\%), with a very even distribution over the various respondents as is illustrated by Table 1, implying that the results can be regarded as a non-biased significant response set that can be used for quantitative analysis. In order to optimise comparability of the Lysons and Meek and Goedegebuure data sets, in this article a reduced data set of the Meek and Goedegebuure study was used, excluding chairmen and 'external' respondents as these were not included in the Lysons data set.

Table 1. Sample statistics

\begin{tabular}{|c|c|c|c|}
\hline \multicolumn{4}{|c|}{ Response by type of institution } \\
\hline & Universities & Colleges \& Institutes & Total \\
\hline Total population & 69 & 117 & 186 \\
\hline Respondents & 47 & 89 & 136 \\
\hline Response rate & $68 \%$ & $76 \%$ & $73 \%$ \\
\hline \multicolumn{4}{|c|}{ Response by function and type of institution in \% } \\
\hline & Universities & Colleges and Institutes & \\
\hline Executive Officer & $65 \%$ & $80 \%$ & \\
\hline Registrar/Secretary & $86 \%$ & $75 \%$ & \\
\hline
\end{tabular}

Data analysis procedures involved two factor analyses of logical sub-sets of the variables. The first addressed variables in the first 4 sections of the questionnaire reflecting transitional aspects of government policy on the system and its institutions in relation to teaching and research, the corresponding effect on funding and resource acquisition, aspects of management methods and the impact on the relative quality of teaching and research. These sections explored issues similar to the organisational effectiveness dimensions underlying the Lysons taxonomy used 
as the framework for this article. The second factor analysis involved all variables (including Section $\mathrm{V}$ dealing with views on the impact of amalgamation) which emerged as statistically significant in explaining differences in the original report (Meek and Goedegebuure 1989: 97-100). Finally, discriminant analysis procedures were applied to each factor structure in order to test their predictive qualities with regard to the 4 group higher education taxonomy emerging from previous research, namely larger/older versus smaller/younger universities, institutes of technology, and colleges (Lysons, 1990b).

\section{Results}

The first round factor analysis produced 4 factors which broadly encompassed (1) competitive aspects relating to quality of teaching and research, (2) funding issues, (3) effectiveness regarding enrolments and management processes, and (4) the issue of institutional autonomy from the government. Following are illustrations of some of the questions put to university and college administrators by the Meek and Goedegebuure study (respondents were asked to indicate their opinions on a fivepoint scale).

Quality of teaching and research:

Increased competition within the higher education system will lead to an improvement of quality with respect to teaching;

Increased competition within the higher education system will lead to an improvement of quality with respect to research;

Present Government policy will enhance the quality of both teaching and research in the higher education system as a whole.

Funding:

The creation of the UNS will insure that institutions are funded for what they do, not on the basis of their sector location;

In ten years time there will be substantial differences in the charges levied on students between subject fields;

In ten years time there will be substantial differences in the charges levied on students between institutions.

Management effectiveness:

In the next ten years institutional management will be strengthened;

At present, the management structures of most institutions inhibit the development of strategic plans;

In the next ten years, strategic planning will be an integral part of institutional management.

Institutional autonomy:

A smaller number of larger higher education institutions will allow the Government greater control over the higher education system;

No longer will institutions have to run to Canberra to get permission to do things which are essentially their own business;

The system of agreed institutional profiles will limit institutional autonomy.

As expected, the factors outlined some of the key issues underlying the 'academic' and 'drawing power' orientations featuring in the previous organisational effectiveness research. Further analysis, however, revealed that the content and orientation of the original organisational effectiveness dimensions were not 
discretely defined sufficient to predict the relevant groups of the taxonomy, in particular the dual leadership dimensions (facilitative supportive - goal directed) which featured so prominently in the original Lysons model. Rather than reflecting major changes in Australian higher education in this respect during the period between the two studies, the lack of prediction power of these discriminant procedures is more likely attributable to the measures themselves, as the Meek and Goedegebuure study was not intended in the first place to capture dimensions of organisational effectiveness, but rather to systematically collect data on the transitional phase of Australian higher education. Therefore, a second procedure, involving the complete data set was tested.

Table 2. Factor structure

\begin{tabular}{|c|c|c|c|}
\hline Factor & Eigenvalue & Variance & Description of variables \\
\hline 1 & 4.20 & $39.1 \%$ & $\begin{array}{l}\text { Mergers are forced through the power of the purse. The } \\
\text { ensuing structure will not improve teaching quality, } \\
\text { research, student or resource opportunities, the } \\
\text { introduction of flexible academic salaries nor } \\
\text { organisational potential, although it might lead to } \\
\text { economies of scale. It will also lead to an increase in } \\
\text { government control. }\end{array}$ \\
\hline 2 & 3.00 & $29.5 \%$ & $\begin{array}{l}\text { Not all higher education institutions should be referred } \\
\text { to as universities. The future Australian higher } \\
\text { education system will see increased difference between } \\
\text { institutions in their teaching and research function, } \\
\text { which should be the case at least with respect to } \\
\text { research, while also there should not be an increased } \\
\text { emphasis on vocational training. In this respect, } \\
\text { amalgamations will not lead to homogeneity, nor is the } \\
\text { elimination of the binary structure desirable. Smaller } \\
\text { governing bodies are not desirable and institutional } \\
\text { autonomy will not increase. }\end{array}$ \\
\hline
\end{tabular}

The second procedure, capturing a more comprehensive reflection of variation in the data set, produced results more consistent with the hypothesised pattern suggested by the OE model. Two factors emerged with eigenvalues greater than 1 , accounting for $68.6 \%$ of variance as outlined in Table 2 . As might be expected, factor 1 includes variables dealing with the financially induced mergers as a result of the government's White Paper, the consequent increase of government control, and disagreements with some possible advantages associated with amalgamations in much of the government's writing on this topic. However, the second factor clearly reflects the binary discussion predominant in the restructuring of Australian higher education. It can be described as 'pro-differentiation' and correspondingly reflects the attitude that differences between institutions in terms of teaching and research are part and parcel of Australian higher education and that this situation 
Table 3. Discriminant analysis of universities versus other institutions

\begin{tabular}{lll}
\hline & \multicolumn{2}{c}{ Predicted group membership } \\
Universities & Institutes \& Colleges \\
Actual Group & & \\
Universities & $63.2 \%$ & $36.8 \%$ \\
Institutes \& Colleges & $6.6 \%$ & $93.5 \%$ \\
\hline Classification function coefficients: & \\
$\quad$ Factor 1 & -0.592 & 0.247 \\
$\quad$ Factor 2 & 1.502 & -0.627 \\
\hline
\end{tabular}

Percent of grouped cases correctly classified: $84.5 \%$

should remain so. Through its structure, factor 2 seems to reflect the 'elitest university stance' regarding the role and functioning of higher education institutions as was also found in the original Lysons study (Lysons, 1990a).

Various discriminant analysis procedures were tested similar to the exploratory Lysons study involving climate dimensions. For example, consistent with the systems resource orientation suggested by the differentiation or - in Australian terms - binary emphasis of the second factor, discrimination of universities versus other institutions was tested (See Table 3). Indeed, the hit rate for correctly predicting cases was $84.5 \%$ based on a single function dominated by factor 2 .

Although a discriminant procedure involving 4 groups reflecting the overall 'life cycle' oriented structure of the taxonomy was unsatisfactory, the role played by the institutes of technology, or DOCIT-institutions as they are known, in the demise of the binary structure, in particular by declaring themselves universities, encouraged a test of colleges versus the three other groups (older and younger universities and

Table 4. Discriminant analysis of colleges versus other institutions

\begin{tabular}{llc}
\hline & $\begin{array}{l}\text { Predicted group membership } \\
\text { Universities \& Institutes }\end{array}$ & Colleges \\
Actual Group & & $32.1 \%$ \\
Universities \& Institutes & $67.9 \%$ & $84.9 \%$ \\
Colleges & $15.1 \%$ & \\
\hline Classification function coefficients: & 0.306 \\
$\quad$ Factor 1 & -0.399 & -0.667 \\
\hline
\end{tabular}

Percent of grouped cases correctly classified: $77.52 \%$

institutes of technology). Again the hit rate for correctly classifying the cases was very strong at $77.5 \%$, whereby according to the expectation factor 2 again dominated the discriminant function (See Table 4). This result is not surprising in that the large institutes of technology, such as John Curtin, Royal Melbourne 
Institute of Technology, and Queensland Institute of Technology, highly resembled the universities in terms of organisational aspirations, while being resentful of their structural location which denied them access to research funding.

\section{Conclusions and discussion}

A taxonomy consisting of four groups of institutions was convincingly empirically established to have existed in Austratian higher education prior to the Dawkins reforms (Lysons, 1990a,; 1990b; 1993). That research program fleshed out the domains of each type of organisation known to exist as the result of the historical development of higher education in Australia (Karmel, 1989) and revealed potentially useful theory explaining the quite different management processes existing in each logical group. This demonstrated the complex mosaic of higher education in Australia and strongly implied distinct and enduring organisational cultures.

However, the Australian higher educational system has changed dramatically in very recent times. The interesting question is whether these changes are more apparent than real. The public debate tends to be rather consistent in the sense that there seems to be general agreement that the binary system as it existed was outmoded. At the same time, there also seems to be general concern about the impact of current developments, where amalgamations among colleges, and between colleges and institutes to form universities may weaken the system in terms of international status (Ward, 1990), and, as importantly, reduce the diversity of institutions and courses (West, 1990a). Furthermore, observers have drawn attention to what they see as tension caused by the cultural revolution of amalgamations involving institutions with radically different organisational cultures (West, 1990b). For example, essentially all amalgamations achieved by early 1991 involved colleges of advanced education and over half were combinations with universities. Table 5 lists the various merger combinations which have occurred or are in the process of being formalised.

While the means used to bring about amalgamation per se is not the subject of this article, it is worthwhile to note that the literature draws a clear distinction between the processes of amalgamation and institutional integration (Carr, 1984; Goedegebuure and Vos, 1988; Harman and Meek, 1988; Harman, 1986; Harman et al., 1985, Meek, 1988, 1989, 1990; Millet, 1975; Shirley and Peters, 1976). Millet (1975) observes that "it is no exaggeration to say that most mergers take about ten years for the wounds to heal and for the new realities to be generally acceptable and workable for faculty, students and staff.' The process of institutional integration following the extensive mergers in Australian higher education will both affect and be affected by the new emerging pattern of institutional categorisation and stratification. This process, in turn, will take place in the context of historically derived definitions concerning institutional goals, missions and management.

The approach adopted in this study was to explore a range of issues which were the targets of change for policy developments, and relate them to the institutional 
Table 5. Members of the UNS, 1991

\begin{tabular}{|c|c|}
\hline Name (and student load ${ }^{a}$ ) & Components \\
\hline Australian Catholic University ${ }^{b}(5,763)$ & $\begin{array}{l}\text { Catholic college of Ed. (NSW) } \\
\text { Institute of Catholic Ed. (VIC) } \\
\text { McAuley College (QLD) } \\
\text { Signadou College (ACT) }\end{array}$ \\
\hline Australian Capital Territory & \\
\hline Australian National University $(7,724)$ & $\begin{array}{l}\text { Australian National University } \\
\text { Canberra Institute of the Arts }\end{array}$ \\
\hline $\begin{array}{l}\text { University of Canberra }{ }^{b}(6,869) \\
\text { New South Wales }\end{array}$ & under the sponsorship of Monash University \\
\hline Charles Sturt University ${ }^{b}(9,800)$ & $\begin{array}{l}\text { Mitchell CAE } \\
\text { Riverina-Murray Institute of Higher Ed. }\end{array}$ \\
\hline MacQuarie University $(10,854)$ & $\begin{array}{l}\text { MacQuarie University } \\
\text { Institute of Early Childhood Studies of Sydney CAE } \\
\text { Sydney College of Chiropractic }\end{array}$ \\
\hline University of New England $(12,315)$ & $\begin{array}{l}\text { University of New England } \\
\text { Armidale CAE } \\
\text { Northern Rivers CAE } \\
\text { Orange Agricultural College }\end{array}$ \\
\hline University of New South Wales $(21,377)$ & $\begin{array}{l}\text { University of New South Wales } \\
\text { City Arts Institute of the NSW Institute of the Arts } \\
\text { St George Institute of Education of Sydney CAE }\end{array}$ \\
\hline University of Newcastle $(10,863)$ & $\begin{array}{l}\text { University of Newcastle } \\
\text { Hunter Institute of Higher Education } \\
\text { Newcastle Branch of the NSW Conservatorium of Music }\end{array}$ \\
\hline University of Sydney $(26,112)$ & $\begin{array}{l}\text { University of Sydney } \\
\text { Cumberland College of Health Sciences } \\
\text { Sydney College of the Arts } \\
\text { State Conservatorium of Music, Sydney } \\
\text { Sydney Institute of Ed., the Institute of Nursing Studies and } \\
\text { Guild Centre of Sydney CAE }\end{array}$ \\
\hline University of Technology, Sydney ${ }^{b}(15,187)$ & $\begin{array}{l}\text { University of Technology, Sydney } \\
\text { Kuring-gai CAE } \\
\text { Institute of Technical and Adult Teacher Education of the } \\
\text { Sydney CAE }\end{array}$ \\
\hline University of Western Sydney $(12,660)$ & $\begin{array}{l}\text { Hawkesbury Agricultural College } \\
\text { Macarthur Institute of Higher Education } \\
\text { Nepean CAE }\end{array}$ \\
\hline $\begin{array}{l}\text { University of Wollongong }(7,859) \\
\text { Victoria }\end{array}$ & \\
\hline University College, Ballarat ${ }^{\mathrm{b}}(3,566)$ & under sponsorship of the University of Melbourne \\
\hline Deakin University $(16,834)$ & $\begin{array}{l}\text { Deakin University } \\
\text { Warrnambool Institute of Advanced Education } \\
\text { Victoria College }\end{array}$ \\
\hline La Trobe University $(17,149)$ & $\begin{array}{l}\text { La Trobe University } \\
\text { Bendigo CAE } \\
\text { Wodonga Institute of Tertiary Education }\end{array}$ \\
\hline Monash University $(26,771)$ & $\begin{array}{l}\text { Monash University } \\
\text { Chisholm Institute of Technology } \\
\text { Gippsland Institute of Advanced Ed. } \\
\text { Victorian College of Pharmacy }\end{array}$ \\
\hline University of Melbourne $(24,513)$ & $\begin{array}{l}\text { University of Melbourne } \\
\text { Hawthorn Institute of Education }\end{array}$ \\
\hline
\end{tabular}


Royal Melbourne Institute of Technology ${ }^{b}$ (recognised as a university $(17,288)$

Victoria University of Technology ${ }^{b}(8,434)$
Victorian College of Agriculture and Horticulture (except Gilbert Chandler)

Victorian college of the Arts

Ballarat CAE as University College

Royal Melbourne Institute of Technology

Philip Institute of Technology

Footscray Institute of Technology

Western Institute

Gilbert Chandler of VCAH

Institutions yet to successfully negotiate merger:

Swinburne Limited ${ }^{\mathrm{b}}(6,086)$

Queensland

University College of Central Queensland ${ }^{\mathrm{b}}(4,743)$

University College of Southern Queensland ${ }^{b}(7,767)$

under sponsorship of the University of Queensiand

Griffith University $(11,584)$

Griffith University

Brisbane CAE (Mt Gravatt)

Gold Coast CAE

Queensland Conservatorium of Music

James Cook University $(5,906)$

Queensland University of Technology $(17,040)$

University of Queensland $(19,668)$

Queensland University of Technology

Brisbane CAE (Kedron Park, Kelvin Grove and Carseldine)

University of Queensland

Queensland Agricultural College

Sponsorship:

University College of Central Queensland (former Capricornia Institute of Advanced Education)

University College of Southern Queensland (former Darling Downs Institute of Advanced Education)

Western Australia

Curtin University of Technology $y^{\mathrm{b}}(12,990)$

Murdoch University $(5,648)$

University of Western Australia (10,517)

Edith Cowan University ${ }^{\mathrm{b}}(11,615)$

South Australia

Flinders University $(8,211)$

Flinders University

Sturt Campus of South Australian CAE

South Australian Institute of Technology

South Australian CAE (Magill, Salisbury and Underdale campuses)

University of Adelaide

Roseworthy Agricultural College

South Australian CAE (city campus)

\section{Tasmania}

University of Tasmania $(9,167)$

University of Tasmania

Tasmania State Institute of Technology

Australian Maritime College ${ }^{c}$

Northern Territory

Northern Territory University $(2,343)$

Urwin Institute of Technology

University College of the Northern Territory 
taxonomy derived from earlier research. As Meek and Goedegebuure indicated in their report, there are commonalities as well as many differences revealed by the data between institutions formerly on either side of the binary line. In this study, these differences systematically co-vary in two factors. On the one hand, and not very surprisingly, considering the effects of the government's White Paper initiatives, there is a general dissatisfaction with the amalgamation process as such, and definite reservations concerning the perceived benefits. More important however, again evidence was found that a strong drive for differentiation exists in Australian higher education. The second factor, possibly representative of universities particularly of the classical variety, strongly suggests that differences in quality and orientation of teaching and research do and should exist. Furthermore, elimination of the 'binary structure' is regarded as undesirable in the sense that all higher educational institutions should not be referred to as universities because in fact mergers are not producing homogeneous organisational outcomes. These factors almost appear to be corollary to each other, particularly if we take into account that the Meek and Goedegebuure study also revealed a basic accordance among respondents on the fact that the Australian system should develop into a more adaptive, responsive and competitive system.

Indeed these dimensions capture a wide range of policy, management and organisational effectiveness, and transitional issues which combined first to reaffirm the systems resource/binary aspects of the Australian higher education taxonomy. Furthermore, the dimensions also discreetly define the colleges of advanced education as being significantly different than the other 3 combined categories. The implications of these findings are important because by longitudinally confirming, and in a sense externally validating the essential elements of the original taxonomy's framework, the systems view which advocates that change occurs slowly and incrementally in institutional arrangements underpinned by strong enduring cultures is also supported.

As interesting from a practical perspective, is how categorically diverse the college perspective is relative to the other 3 groups. This finding is particularly important in view of the fact that, as stated before, all amalgamations either involve colleges with organisations from other categories, or involve combining several colleges under a university banner or at least sponsored by a larger host as a university college. Of the plausible alternative amalgamation combinations, colleges are most unique relative to the rest, and least like the university model they are being encouraged to emulate. In this context, the many concerns being registered regarding the organisational tensions accompanying amalgamation take on the air of being rather well informed (Francis and West, 1990).

Despite what the critics may have to say about its desirability, it appears that all institutions joining the UNS will be called 'universities.' But the UNS is itself a misnomer; the system will not be 'unified,' but characterized by fierce institutional competition over scarce resources and prestige. Government policy is designed to ensure that this occurs. The teaching/research nexus in terms of funding has been broken, and progressively money for research will be allocated on a competitive basis. Quality measurement mechanisms presently being formulated for both 
teaching and research will play a role in future funding allocations.

There was no unity, and certainly no uniformity, in the 'old' system either, particularly with regard to funding. In the past, funding per student place in the same or similar disciplinary area differed up to 30 per cent between institutions. In order to correct historical funding imbalances and to ensure that the new game played under the banner of the UNS occurs on a 'level playing field,' the federal government has introduced the 'Relative Funding Model' as a one off exercise to operate up to the end of 1992 (DEET, 1990). Its primary purpose is to iron out past funding inequities. Funding levels will reflect the Relative Funding Model (94\%) and a research component based on a competitive grants index $(6 \%)$.

It is not clear what kind of funding model will operate after 1992. But out of the institutional reshuffling that has occurred over the last four years one can identify four types of competitors for public funding and prestige: (1) the older research universities (e.g. Sydney and Melbourne); (2) the universities of technology (e.g., Queensland University of Technology [formerly Queensland Institute of Technology] and Curtin University of Technology [formerly Western Australia Institute of Technology]); (3) universities on the social and geographical fringe of the higher education system (e.g., Deakin and the University of New England); and (4) CAE combinations redesignated as universities (e.g., the University of Western Sydney and Edith Cowan University). Of course, the existence of this taxonomy has not yet been empirically tested, but it is intuitively derived from the empirical studies discussed earlier in this article. If it turns out that the new higher education taxonomy is but a mirror image of that which existed pre-Dawkins, the effectiveness and the expense of the dramatic restructuring of recent years may be brought into question.

It should be noted that an institution's size (see Table 5) supposedly will influence its mission and ability to compete, particularly with regard to research. The Government's Green Paper (1987: 34) stipulated the following size criteria for entry to and performance in the UNS:

- 5000 EFTSU for an institution to have a broad teaching profile with some specialised research activity;

and

- 8000 EFTSU for a relatively comprehensive involvement in teaching and with resources to undertake research across a significant proportion of its profile.

The new typology emerging from the restructuring process could easily form a de facto binary system (Scott, 1988), particularly if research remains as the essential criteria for the allocation of status and prestige (see Harman and Wood, 1990): a development which, in fact, is expected to occur according to a large majority of the key position holders in Australian higher education. $70 \%$ of the survey respondents indicated that the old binary system will be replaced by a new one, resulting in a system in which only a few institutions are funded for the full range of teaching and research activities, with the rest of the institutions confined to mainly teaching (Meek and Goedegebuure, 1989: 79). This new binary line, if it 
emerges, would be a reflection of historical divisions, with some variation. Mergers involving the older universities and institutes of technology will probably have little effect on their goals, missions and management orientations. These institutions are more likely to colonise than truly amalgamate with their respective CAE partners. The newer universities and the regional universities are in a more precarious position, as they were in the past. Although they pretended otherwise, these institutions were never equal competitors with the older research universities, and they may find that their amalgamation partners have a powerful voice in deciding future directions. The CAEs redesignated as universities must now formulate their goals, missions and management orientations, and the question is whether these will be but a pale imitation of those existing in the research universities or a creative response to new circumstances. Powerful forces push institutions towards imitation of those at the top of the status hierarchy (Clark, 1983; DiMaggio and Powell, 1983; Neave, 1983). What is at stake, as Clark (1983: 194-195) notes, is the 'legitimation of roles for different types of institutions.'

It is too early to provide a clear picture of what the new order of Australian higher education may look like. There is little doubt that the older research universities will be placed at the top of the hierarchy, but what will happen below these few prestigious institutions remains to be seen. If those institutions which cannot occupy the top rung in the status ladder do not develop a distinctive identity and mission seen as a legitimate alternative by staff, students and the community, then all the effort and pain brought about through a government's restructuring of the system will have been wasted. In order for the system to survive and prosper it probably needed to change. But the concept of equifinality in systems theory suggests a range of equally plausible paths or solutions to achieve the ultimate outcome desired.

With respect to diversification, the mere existence of distinct organisational types may suggest that the policy is being achieved. But this is not necessarily the case. Distinct types of institutions within the 'old' binary system did not prevent institutional imitation, nor will it do so for the UNS. What is at stake is not the 'type' of institution but the reward structure governing institutional competition. The taxonomy is important, however, in that not all institutions will be in an equally advantageous position to compete for the same scarce resources. If institutions lacking capacity for certain tasks nonetheless feel that they must engage in those tasks - such as research - in order to financially survive, then both diversity and quality are likely to be reduced.

There is some evidence to suggest that the Australian higher education reward structure is working against diversity. The external policy environment is somewhat contradictory in this respect. For example, research funding has become more competitive, while at the same time every institution is attempting to build a research culture. The new universities formed through amalgamation of former CAEs are shifting resources in order to develop research centres. Each year the number of research proposals from staff in these institutions to competitive research funding agencies, such as the Australian Research Council, rises. Due to the fact that funding per EFT is higher for a PhD enrolment than for an 
undergraduate enrolment, the new universities are developing $\mathrm{PhD}$ programs and shifting student load to these programs. Within 'older' university/CAE amalgamations, most ex-CAE staff feel compelled to become researchers. Other examples of policies which appear to encourage institutional imitation could be provided and, of course, there is a need to collect much more empirical data on these issues. But the main point is that present government policies may not be building on the diversity already present in the system; rather, policies may soon lead Australian higher education to the same crises point that precipitated the 1987 reforms.

\section{Acknowledgement}

The authors gratefully acknowledge the time and energy invested by the various institutions and individual respondents in the empirical studies. In particular, Art Lysons acknowledges the support provided by the School of Business, Queen's University at Kingston and its D.I. McLeod Research Assistance program. The present article is a revised version of a paper presented at the 13th International EAIR Forum in Edinburgh, September 1-4, 1991.

\section{References}

Cameron, K.S. (1978). 'Measuring organisational effectiveness in institutions of higher education', Administrative Science Quarterly 23, $604-632$.

Cameron, K.S. (1981). 'Domains of organisational erffectiveness in colleges and universities', Academy of Management Journal 24(1), 25-47.

Cameron, K.S. (1986). 'A study of organisational effectiveness and its predictors', Management Science $32,87-112$.

Cameron, K.S., and Ettington, D.R. (1989). 'The conceptual foundations of organisational culture', in Smart, J.C. (ed.), Higher Education: Handbook of Theory and Research, Agathon Press: New York. pp. 356-396.

Cameron, K.S., and Whetten, D.A. (1981). 'Perceptions of organisational effectiveness over organisational life cycles', Administrative Science Quarterly 26, 525-544.

Carr, N.H. (1984). A merger between the new university of Ulster and Ulster Polytechnic: Possibilities and constraints for higher education planners. Ph.D. dissertation, Michigan State University.

Clark, B.R. (1983). The Higher Education System. Berkeley: University of California Press.

Dawkins, J. (1987). Higher Education: a policy discussion paper [Green Paper]. Canberra: AGPS.

Dawkins, J. (1988). Higher Education: a policy statement [White Paper]. Canberra: AGPS.

Department of Employment, Education and Training (1990). Relative Funding Model. Canberra: AGPS.

DiMaggio, P.J., and Powell, W.W. (1983). 'The iron cage revisited: Institutional isomorphism and collective rationality in organizational fields', American Sociological Review 48, 147-160.

Francis, R., and West, W. (1990) 'Amalgamation tensions now "time bombs", Higher Education Supplement, The Australian 522, 15.

Goedegebuure, L.C.J., and Meek, V.L. (eds.) (1987) Change in higher education; the non-university sector: An international perspective. Culemborg: Lemma.

Goedegebuure, L.C.J., and Meek, V.L. (1991) 'The restructuring of higher education, a comparative analysis between Australia and The Netherlands', Comparative Education 27(1), 7-22.

Harman, G., and Wood, F. (1990). 'Academics and their work under Dawkins: A study of five NSW 
universities', Australian Educational Researcher 17(2), 53-76.

Harman, G. (1986). 'Restructuring higher education system through institutional mergers: Australian experience (1981-1983)', Higher Education 15, 567-586.

Harman, G. (1991). 'Institutional amalgamations and abolition of the binary system in Australia under John Dawkins', Higher Education Quarterly 45(2), 176-198.

Harman, G., Beswick, D., and Schofield, H. (1985). The Amalgamation of Colleges of Advanced Education at Ballarat and Bendigo, Parkville: Centre for the Study of Higher Education, University of Melbourne.

Harman, G., and Meek, V.L. (1988). 'Lessons from recent experience with mergers', in Harman, G., and Meek, V.L. (eds.) Australian Higher Education Reconstructed?, Armidale, University of New England. pp. 111-121.

Karmel, P. (1989). Reflections on a revolution: Australian higher education in 1989. AVCC Papers, No. 1, Australian Vice-Chancellors' Committee.

Lysons, A.F. (1990a). 'Taxonomies of higher educational institutions predicted from organisation climate', Research in Higher Education 31(2), 115-128.

Lysons, A.F. (1990b). 'Dimensions and domains of organisational effectiveness in Australian higher education', Higher Education 20(3), 287-300.

Lysons, A.F. (1993). 'The typology of organisational effectiveness in Australian higher education', Research in Higher Education (in press).

Lysons, A.F., and Ryder, P.A. (1988). 'An empirical test of Cameron's dimensions of effectiveness: Implications for Australian tertiary institutions', Higher Education 17(3), 323-332.

Lysons, A.F., and Ryder, P.A. (1989). 'An application of Jones and James' perceived climate questionnaire in Australian higher educational institutions', Higher Education 18(6), 697-705.

McKelvey, B. (1975). 'Guidelines for the empirical classification of organisations', Administrative Science Quarterly 20, 509-525.

Meek, V.L. (1988). 'Comparative notes on cross-sectoral amalgamation of higher education institutions: British and Australian case studies', Comparative Education 24(3), 335-349.

Meek, V.L. (1989). 'Institutional amalgamation in higher education', Journal of Education Policy 4(1), 23-27.

Meek, V.L. (1990). 'The rise and fall of the binary policy of higher education in Australia', Journal of Education Policy 5(3), 282-292.

Meek, V.L. (1991). 'The transformation of Australian higher education: From binary to unitary system', Higher Education 21(4), 461-494.

Meek, V.L., and Goedegebuure, L.C.J. (1989). Higher Education: A Report, Department of Administrative and Higher Education Studies, University of New England.

Millett, J.D. (1975). Mergers in Higher Education: An Analysis of Ten Case Studies, Washington: Academy for Educational Development.

Neave, G. (1983). 'The dynamics of integration in non-integrated systems of higher education in Western Europe', in Hermanns, H., Teichler, U., and Wasser, H. (eds.), The Compleat University. Cambridge, Massachusetts: Schenkman. pp. 263-276.

Pfeffer, J., and Salancik, G.R. (1978). The External Control of Organizations: A Resource Dependence Perspective, New York: Harper and Row Publishers.

Quim, R.E., and Cameron, K.S. (1983). 'Organisational life cycles and shifting criteria of effectiveness: Some preliminary evidence', Management Science 29(1), 33-51.

Quinn, R.E., and Rohrbaugh, J. (1983). 'A spatial model of effectiveness criteria: Toward a competing values approach to organisational analysis', Management Science 29(3), 363-377.

Report of the Task Force on Amalgamations in Higher Education (1989). Canberra: AGPS.

Scott, R. (1988). 'The New Binarism?' in Harman, G., and Meek, V.L. (eds.) Australian Higher Education Reconstructed? Armidale: University of New England.

Shirley, R.C., and Peters, W.M. (1976), 'University merger: A case of organisational change', College and University 51(2).

Vught, F.A. van (ed.) (1989). Governmental Strategies and Innovation in Higher Education. London: Jessica Kingsley.

Ward, Emeritus Professor J. (1990). 'What's "good" for nation can be bad for unis', Higher Education 
Supplement The Australian, 523, 16.

West, W. (1990a). 'Birt champions uni return to binary ways', Higher Education Supplement The Australian, 523, 15.

West, W. (1990b). 'Uni stature "diminished by cultural revolution"', Higher Education Supplement The Australian, 523, 15.

Yuchtman, E., and Seashore, S.E. (1967). 'A system resource approach of organisational effectiveness', American Sociological Review 32, 891-903. 